\title{
ЭНТЕРОВИРУСЫ ЧЕЛОВЕКА ПРОЯВЛЯЮТ ИЗБИРАТЕЛЬНУЮ ОНКОЛИТИЧЕСКУЮ АКТИВНОСТЬ НА МОДЕЛИ КСЕНОТРАНСПЛАНТАТОВ МУЛЬТИФОРМНОЙ ГЛИОБЛАСТОМЫ ЧЕЛОВЕКА В ИММУНОДЕФИЦИТНЫХ МЫШАХ
}

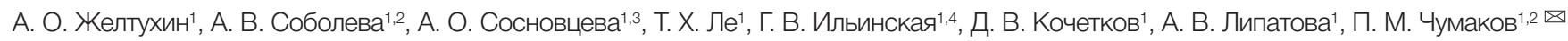 \\ 1 Институт молекулярной биологии имени В. А. Энгельгардта, Москва \\ 2 Федеральный научный центр исследований и разработки иммунобиологических препаратов имени М. П. Чумакова, Москва \\ ${ }^{3}$ Российский национальный исследовательский медицинский университет имени Н. И. Пирогова, Москва \\ ${ }^{4}$ Российский онкологический центр имени Н. Н. Блохина, Москва
}

\begin{abstract}
Основным источником возникновения рецидивов мультиформной глиобластомы после хирургического вмешательства являются стволовые клетки, успевающие проникнуть глубоко в ткани мозга. В настоящее время актуален поиск новых подходов для борьбы с ними, в том числе с помощью онколитических вирусов. Целью работы было определение чувствительности к непатогенным энтеровирусам клеток мультиформной глиобластомы человека, поддерживаемых in vitro и в модели мышиных ксенотрансплантатов. Культуры опухолевых клеток глиобластом испытывали на чувствительность к полиовирусу 1 типа (штамм вакцины Сэбина), вирусу Коксаки А7 (штамм ЖЭВ8), Коксаки А9 (штамм ЖЭВ9) и Коксаки В5 (Штамм ЖЭВ12). Количественную оценку репродукции вирусов и их цитолитическую активность проводили заражением монослойных культур клеток глиобластомы. Эффективность уничтожения стволовых клеток глиобластомы определяли по способности клеточных культур глиобластом, обогащенных опухолевыми стволовыми клетками, формировать подкожные опухоли у иммунодесицитных мышей после обработки вирусами. По результатам исследования наиболее выраженная онколитическая и репликационная активность выявлена у вируса Коксаки А7 и полиовируса 1 типа при тестировании в модели культур клеток глиобластом, инфицированных вирусами in vitro, а также in vivo, в модели подкожных опухолевых ксенотрансплантатов на иммунодесицитных мышах. Полиовирус 1 типа и вирус Коксакси А7 предотвращали образование опухолей после того как нейросферные культуры клеток глиобластом преинкубировали с вирусами перед подкожным введением. Вирус Коксаки В5 вызывал лишь частичное сокращение числа опухолей, а Коксаки А9 не влиял на опухолеобразование. Таким образом, ряд штаммов непатогенных энтеровирусов способен уничтожать стволовые клетки глиобластом и представляется перспективным при разработке терапевтических средств для безрецидивного лечения глиобластом.
\end{abstract}

Ключевые слова: мультисормная глиобластома, онколитический вирус, непатогенные энтеровирусы, персонифицированная медицина, рецидив опухоли, экспериментальная терапия рака

Финансирование: работа выполнена при финансовой поддержке Министерства образования и науки РФ, уникальный код проекта RFMEFI60714Х0014.

$凶$ Для корреспонденции: Петр Михайлович Чумаков

ул. Вавилова, д. 32, г. Москва, 119991; chumakovpm@yahoo.com

Статья получена: 26.06.2018 Статья принята к печати: 30.06.18

DOI: $10.24075 /$ vrgmu.2018.026

\section{HUMAN ENTEROVIRUSES EXHIBIT SELECTIVE ONCOLYTIC ACTIVITY IN THE MODEL OF HUMAN GLIOBLASTOMA MULTIFORME XENOGRAFTS IN IMMUNODEFICIENT MICE}

Zheltukhin $A O^{1}$, Soboleva $A V^{1,2}$, Sosnovtseva $A O^{1,3}$, Le TH ${ }^{1}$, Ilyinskaya GV ${ }^{1,4}$, Kochetkov DV¹, Lipatova AV1, Chumakov PM ${ }^{1,2} \bowtie$

Engelhardt Institute of Molecular Biology, Russian Academy of Sciences, Moscow

Chumakov Federal Scientific Center for Research and Development of Immune-and-Biological Products, Moscow

${ }^{3}$ Pirogov Russian National Research Medical University, Moscow

Blokhin National Medical Research Center of Oncology, Moscow

Stem cells that penetrated deeply into the brain tissue are the main reason behind the relapses of glioblastoma multiforme after surgery. Finding new approaches to counter such relapses, including those that make use of oncolytic viruses, is a pressing issue. This study aimed to determine the sensitivity of cells of human glioblastoma multiforme to non-pathogenic enteroviruses, in vitro and in vivo (mice xenografts model). Glioblastoma tumor cells were exposed to type 1 poliovirus (Sabin vaccine strain), Coxsackie virus A7 (strain LEV8), Coxsackie virus A9 (strain LEV9) and Coxsackie virus B5 (strain LEV14). The virus reproduction intensity and cytolytic activity were assessed through infection of monolayered glioblastoma cell cultures. The ability of glialoblastoma cell cultures (enriched with tumor stem cells) to build subcutaneous tumors in immunodeficient mice after those cultures were exposed to viruses signaled the effectiveness of glioblastoma stem cells destruction. The study revealed that Coxsackie virus A7 and type 1 poliovirus possess the most pronounced oncolytic and replicative properties when tested on gliblastoma cells infected with viruses in vitro and on subcutaneous tumor xenografts in immunodeficient mice (in vivo). Type 1 poliovirus and Coxsackie virus A7 virus prevented development of tumors when glioblastoma neurospheric cell cultures were preincubated with viruses before subcutaneous implantation. Coxsackie virus B5 only managed to reduce the number of tumors developed, and Coxsackie virus A9 did not affect the tumor development at all. Thus, a number of non-pathogenic enteroviruses strains can destroy glioblastoma's stem cells, i.e. they show promise in the context of development of therapeutic agents for relapse-free treatment of glioblastomas.

Keywords: glioblastoma multiforme, oncolytic virus, non-pathogenic enteroviruses, personalized medicine, tumor relapse, experimental cancer therapy

Funding: the study was supported by the Ministry of Education and Science of the Russian Federation; project code RFMEFI60714X0014.

$\triangle$ Correspondence should be addressed: Peter M Chumakov

Vavilova, 32, Moscow, 119991; chumakovpm@yahoo.com

Received: 26.06.2018 Accepted: 30.06.18

DOI: $10.24075 /$ brsmu.2018.026 
Терапия опухолей головного мозга по-прежнему остается проблемной, особенно в случае мультиформной глиобластомы, наиболее злокачественной и практически неизлечимой болезни [1]. Инфильтративный рост и расположение в функционально важных областях мозга делают эти опухоли чрезвычайно сложными для хирургического вмешательства. Из-за опасности возникновения неврологических нарушений хирургическое лечение часто ограничивается лишь частичным удалением опухоли. Однако даже в случаях радикального удаления рецидивы заболевания неизбежны, так как инициирующие опухоль стволовые клетки глиобластомы глубоко мигрируют в здоровые области мозга и не могут быть удалены [2-4]. Химио- и радиотерапия также приводят лишь к краткосрочным ремиссиям, после которых неизбежен вторичный рост [4]. Существующие в настоящее время варианты лечения глиобластом почти исчерпаны, что оправдывает поиск новых альтернативных подходов для избирательного и эффективного уничтожения злокачественных клеток. Значительный прогресс в понимании механизмов злокачественного роста и специсических свойств клеток глиобластомы является хорошей основой для разработки инновационных терапевтических подходов. Среди них особенно многообещающим является использование непатогенных онколитических вирусов, которые специсически распознают и уничтожают клетки глиобластомы [5, 6].

Онколитические вирусы для лечения глиом человека разрабатываются на основе вирусов, принадлежащих ко многим семействам, и включают вирусы герпеса, вирус болезни Ньюкасла [7-11], аденовирусы [12-16], парвовирусы [17-19], реовирусы [20-23], энтеровирусы [24-27] и другие [1]. Многочисленные клинические испытания показали отсутствие токсичности препаратов онколитических вирусов [28-31]. Кроме того, в отличие от химио- и таргетной терапии многие онколитические вирусы способны эффективно убивать инициирующие опухоль стволовые клетки [16, 32-37], что безусловно важно для полного излечения пациентов. В настоящее время уже существует широкий арсенал потенциальных вирусных терапевтических штаммов, которые могут быть использованы для дальнейших клинических испытаний. В настоящее время активно изучаются свойства непатогенных штаммов вирусов Коксаки (в частности, А7, A9 и B5), и предварительные данные свидетельствуют о том, что они являются потенциальными терапевтическими агентами [38].

Целью данного исследования было испытание чувствительности опухолевых клеток глиобластомы к онколитическому действию ряда непатогенных онколитических энтеровирусов в моделях in vitro и in vivo с целью оценки перспектив использования этих вирусов в качестве терапевтических средств для лечения глиобластом.

\section{МАТЕРИАЛЫ И МЕТОДЫ}

\section{Получение первичных клеточных культур из опухолей глиобластомы}

Фрагменты свежеудаленных у пациентов опухолей хранили не более 12 ч в охлажденной стерильной культуральной среде. Кусочки опухоли механически отделяли от участков некроза, элементов стромы, кровеносных сосудов, и измельчали путем аккуратного продавливания через нейлоновую сетку с размером пор 50 мкм. Суспензию агрегатов опухолевых клеток промывали изотоническим фоссратным бусерным раствором (PBS) и инкубировали в 25 объемах раствора коллагеназы 4 (ПанЭко, Москва) в течение 25 мин при $30^{\circ} \mathrm{C}$. Для получения монослойных культур клеток глиобластомы обработанную коллагеназой суспензию дважды промывали средой DMEM (ПанЭко, Москва) и помещали в среду DMEM-F12, добавив 10\% эмбриональной сыворотки теленка и по 100 мкг/мл пенициллина и стрептомицина при плотности $10^{5}$ кл/мл. Планшеты инкубировали в атмосфере $5 \% \mathrm{CO}_{2}$ при $37^{\circ} \mathrm{C}$ с заменой среды через каждые 4 дня, до образования монослоев. Монослойные культуры устанавливали примерно через 18-25 дней инкубации на 10-сантиметровых культуральных чашках.

\section{Рост опухолевых ксенотрансплантатов на иммунодефицитных мышах}

Ксенотрансплантаты подкожных опухолей получали в результате инъекции нейросфер, образованных из глиобластом путем альтернативного способа высевания клеток после обработки фрагментов опухоли коллагеназой 4 (ПанЭко, Москва). Клетки высевали в плотности $10^{4}$ кл./ мл В среду DMEM-F12 с добавлением по 100 мкг/мл пенициллина и стрептомицина, 20 нг/мл эпидермального фактора роста (EGF) и 10 нг/мл фактора роста фибробластов (bFGF). Культуры выдерживали в CO2-инкубаторе при $37^{\circ} \mathrm{C}$ в течение 2 недель с заменой среды каждые 4 дня до появления видимых нейросфер. Нейросферы обогащены стволовыми клетками глиобластомы и обладают повышенной опухолегенной активностью при инъекции иммунодефицитным мышам. Для имплантации нейросферы дважды промывали PBS, подсчитывали с помощью гемоцитометра и по 200 нейросфер вводили подкожно в плечевую область 3-5-недельных бестимусных мышей линии Balb/c. Рост опухоли контролировали каждые 3 дня, а общее количество опухолей оценивали на 21-й день.

\section{Штаммы онколитических вирусов}

В работе использовали непатогенные штаммы энтеровирусов человека из коллекции лаборатории: полиовирус 1 типа (вакцинный штамм Сэбина), вирусы Коксаки А7 (штамм ЖЭВ8), Коксаки А9 (штамм ЖЭВ9) и Коксаки В5 (штамм ЖЭВ14) [38, 39]. Энтеровирусы выращивали в клетках Vero. Вирусные титры, выраженные как TCID50/мл, определяли путем инфицирования клеток Vero серийными разведениями вирусосодержащей жидкости.

\section{Испытание чувствительности клеток глиобластом к вирусам}

Для определения дифференциальной чувствительности к панели онколитических энтеровирусов опухолевых клеток, прошедших после эксплантации минимальное число пассирований в культуре, был использован опухолевый материал от двух пациентов с глиобластомами. Полученные от этих пациентов культуры обозначались как GM-3564 и GM-3876. Заражение культур проводили в 96-луночных планшетах для культивирования клеток (SPL Lifesciences, Республика Корея). Субконфлюэнтные однодневные монослои культур клеток GM-3564 и GM-3876, а также контрольных клеток Vero инкубировали с 0,1 мл серийных разведений вирусов. Спустя 7 ч после заражения культур серийными десятикратными разведениями вирусных препаратов, представляющих четыре непатогенных энтеровируса, 
определяли жизнеспособность клеток Цитопатическую активность оценивали через 72 ч с помощью набора реагентов для оценки жизнеспособности клеток (CellTiter$\mathrm{GlO}^{\circledast}$ Luminescent Cell Viability Assay, Promega, CШA), согласно рекомендациям производителя.

\section{Введение вируса in vivo}

Для измерения способности вирусов предотвращать образование опухолей при введении нейросфер, перед подкожным введением нейросферы инкубировали с вирусами $\left(2 \times 10^{6}\right.$ инфекционных единиц (и.е.) вирусов в объеме 0,1 мл в течение 30 мин при $37^{\circ} \mathrm{C}$ ).

\section{РЕЗУЛЬТАТЫ ИССЛЕДОВАНИЯ}

Полученные из опухолевого материала двух пациентов монослойные культуры глиобластом были испытывали на чувствительность к четырем штаммам энтеровирусов. Для клеток GM-3564 наиболее сильную литическую активность оказывал вирус Коксаки А7, несколько более слабую проявлял полиовирус 1 типа (рис. 1) В культуре GM-3876 наблюдали противоположную картину: в этих клетках наиболее сильной инфицирующей и литической активностью обладал полиовирус 1 типа, тогда как вирус Коксаки А7 демонстрировал аналогичное действие только при дозах вируса, приблизительно в десять раз больших. Обе культуры были относительно устойчивы к действию вируса Коксаки В5 и почти полностью устойчивы К вирусу Коксаки А9. Этот последний штамм вируса оказывал небольшоетоксическоедействиетолькопримаксимальных дозах. Между тем, при инфицировании теми же дозами вирусов контрольной культуры клеток Vero все четыре вируса начинали оказывать цитотоксическое действие при примерно одинаковых дозах. Таким образом, две культуры глиобластом обладают явной селективностью в отношении их способности инфицироваться и лизироваться различными вирусными штаммами, что, по-видимому, обусловлено различием в их способности поддерживать репликацию этих вирусов.

Чтобы установить способность вирусных штаммов предотвращать образование подкожных опухолей при инъекции ксенотрансплантатов иммунодесицитным мышам, из опухолевого материала пациентов с глиобластомой получили культуры нейросфер. Нейросферы обогащены опухолеобразующими стволовыми клетками, и поэтому

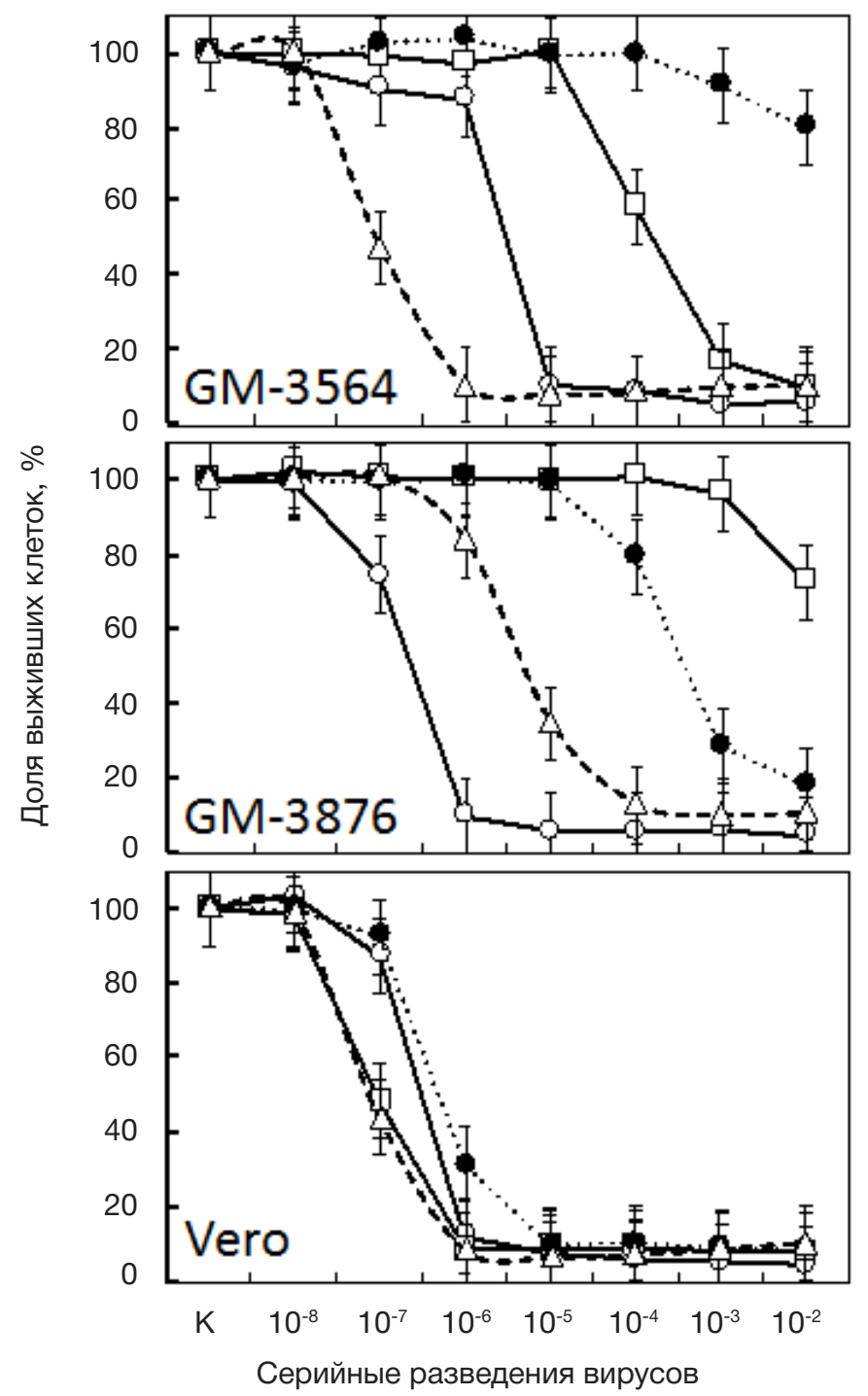

Рис. 1. Чувствительность монослойных культур ранних пассажей, полученных от двух пациентов с глиобластомами, к четырем штаммам онколитических энтеровирусов: - О- - полиовирус 1 типа; - - $\triangle$ - - вирус Коксаки А7; - $\square-$ — вирус Коксаки А9; .... ... Вирус Коксаки В5. Горизонтальная ось: 10-8-10-2 - десятикратные серийные разведения вирусных препаратов, использованные для заражения. Vеrо - контрольная культура клеток чувствительная ко всем четырем типам вирусов 


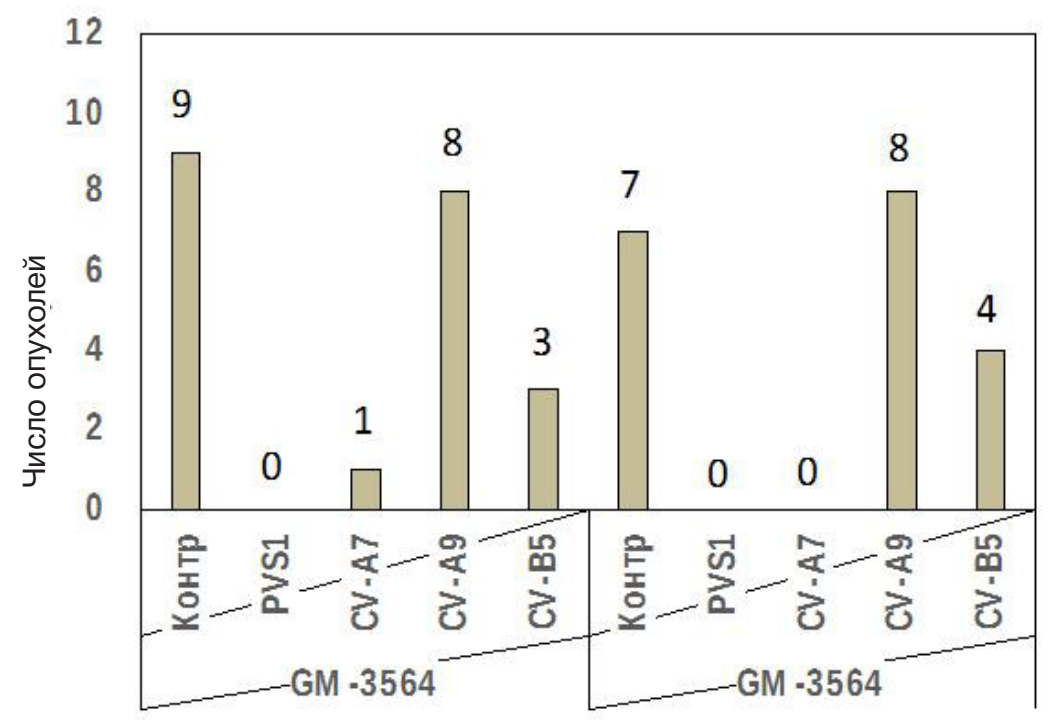

Рис. 2. Тест на подавление опухолеобразования нейросфер глиобластом после их предобработки каждым из четырех вирусов перед подкожной инъекцией иммунодефицитным мышам. Столбики отражают число опухолей, образовавшихся в каждой группе мышей, контрольных (Контр) и после обработки вирусами. PVS1 - полиовирус 1 типа; CV-A7 - вирус Коксаки A7; CV-A9 - вирус Коксаки A9; CV-B5 — вирус Коксаки B5

их опухолегенность значительно выше по сравнению с монослойными культурами клеток глиобластом. Чтобы получить культуры нейросфер, среда должна содержать специфические ростовые факторы EGF и bFGF. Кроме того, при получении нейросфер из фрагментов опухоли больного требуется произвести рассев в пластиковую посуду, не поддерживающую прикрепление клеток. В таких условиях клетки глиобластом образуют сфероидные агрегаты, или нейросферы, состоящие из многих клеток, причем нейросферы обогащенны опухолеобразующими стволовыми клетками. Поскольку подсчет числа отдельных клеток в сфероидах затруднен, для стандартизации процедуры подкожного введения с целью получения опухолей мы проводили подсчет самих нейросфер. В нашем предварительном исследовании было установлено, что введение 200 нейросфер воспроизводимо приводит к образованию опухолей в течение 1-2,5 недель. Контрольной группе из пяти мышей вводили подкожно в область плеча с обеих сторон по 200 нейросфер в объеме 0,5 мл. Такое же число мышей использовали при испытании влияния вирусов на опухолеобразование. Таким образом, в каждой группе мышей могло образовываться до 10 опухолей. Чтобы проверить способность вирусов предотвращать образование опухолей из инъецированных нейросфер, последние инкубировали с вирусами (см. «Материалы и методы»). Для каждого типа вирусов использовали пять мышей, которых инъецировали в две точки суспензией, содержащей обработанные вирусами нейросферы, и подсчет образовавшихся опухолей проводили через 21 день после инъекций. Оценка опухолей не включала измерение их размеров (рис. 2). В контрольной группе мышей, инъецированных нейросферами клеток GM-5564, образовалось 9 опухолей (из 10 возможных). Обработка полиовирусом 1 типа полностью подавляла образование опухолей, а после обработки вирусом Коксаки А7 появилась только одна опухоль, причем на более позднем сроке. После обработки вирусом Коксаки В5 образовалось три опухоли, а вирус Коксаки А9 практически не препятствовал формированию опухолей (8 опухолей). Принципиально похожие результаты мы наблюдали в группах мышей, которым вводили нейросферы клеток GM-3876: в контрольной группе образовалось 8 опухолей (из 10 возможных); после обработки полиовирусом и вирусом Коксаки А7 опухоли отсутствовали; в группе, обработанной вирусом Коксаки В5, появилось 4 опухоли, а вирусом Коксаки А9 - 8 опухолей.

\section{ОБСУЖДЕНИЕ РЕЗУЛЬТАТОВ}

Культуры нейросфер являются наиболее адекватной моделью для анализа терапевтического потенциала средств борьбы с глиобластомами [40]. Это объясняется тем, что нейросферы обогащены опухолевыми стволовыми клетками, которые служат основным источником рецидива заболевания вследствии их особой устойчивости к большинству терапевтических воздействий [41]. В данном исследовании мы провели анализ способности четырех непатогенных онколитических энтеровирусов предотвращать образование экспериментальных подхожных опухолевых ксенотрансплантатов, полученных при введении нейросфер, образовавшихся из опухолевого материала двух больных глиобластомой. Полученные данные указыват на высокий потенциал двух вирусных штаммов полиовируса 1 типа и вируса Коксаки А7. Однако нейросферы от двух разных больных демонстрировали различную степерь чувствительности к этим вирусам, что указывает на необходимость персонифицированного подбора наиболее эффективных терапевтических штаммов после предварительного анализа биопсийного или операционного материала, полученного из опухолей пациентов. Недавно опубликованные результаты клинических испьтаний рекомбинантного полиовируса PVSRIPO указывают на возможность длительных ремиссий у 21\% больных глиобластомами, в то время как у остальных пациентов полиовирус не оказывал терапевтического действия [42]. Дополнение арсенала терапевтических штаммов вирусами, обладающими иными спектрами воздействия на опухоли, сможет существенно повысить процент случаев, поддающихся успешному лечению этого заболевания.

\section{ВЫВОДЫ}

По результатам проведенного исследования можно сделать вывод о том, что способность каждого из четырех штаммов непатогенных онколитических энтеровирусов оказывать цитолитическое действие в монослойных культурах 
клеток глиобластом человека хорошо коррелирует со способностью тех же штаммов предотвращать образование опухоли в результате ксенотрансплантации иммунодесрицитным мышам. Таким образом, существует явная взаимосвязь между эффектами вирусов in vitro и их онколитической активностью in vivo. Кроме того, обнаружено, что вирусы, которые могут эффективно реплицироваться в монослойных культурах клеток глиобластом, способны эффективно убивать опухолеобразующие стволовые клетки глиобластом, что указывает на высокий потенциал онколитических вирусов в предотвращении рецидивов опухоли. Различия в чувствительности к вирусам опухолевых клеток, полученных от двух пациентов, указывают на необходимость персонифицированного подбора терапевтических штаммов.

\section{Литература}

1. Губанова Н. В., Гайтан А. С., Разумов И. А., Мордвинов В. А., Кривошапкин А. Л., Нетесов С. В., и др. Онколитические вирусы в терапии глиом. Молекулярная биология. 2012; 46 (6): 726-38.

2. Greenberg MS. Handbook of Neurosurgery. 7th ed. New York: Thieme Publishers; 2010.

3. Park DM, Rich JN. Biology of glioma cancer stem cells. Molecules and cells. 2009; 28 (1): 7-12. DOI: 10.1007/s10059-009-0111-2. PubMed PMID: 19655094

4. Claes A, Idema AJ, Wesseling P. Diffuse glioma growth: a guerilla war. Acta Neuropathol. 2007; 114 (5): 443-58. DOI: 10.1007/ s00401-007-0293-7. PubMed PMID: 17805551; PubMed Central PMCID: PMCPMC2039798.

5. Buonaguro FM, Tornesello ML, Izzo F, Buonaguro L. Oncolytic virus therapies. Pharmaceutical patent analyst. 2012; 1 (5): $621-$ 27. DOI: 10.4155/ppa.12.65. PubMed PMID: 24236929.

6. Parker JN, Bauer DF, Cody JJ, Markert JM. Oncolytic viral therapy of malignant glioma. Neurotherapeutics. 2009; 6 (3): 558-69.

7. Zulkifli MM, Ibrahim R, Ali AM, Aini I, Jaafar H, Hilda SS, et al. Newcastle diseases virus strain V4UPM displayed oncolytic ability against experimental human malignant glioma. Neurological research. 2009; 31 (1): 3-10. DOI: 10.1179/174313208×325218. PubMed PMID: 18937888.

8. Wagner S, Csatary CM, Gosztonyi G, Koch HC, Hartmann C Peters $\mathrm{O}$, et al. Combined treatment of pediatric high-grade glioma with the oncolytic viral strain $\mathrm{MTH}-68 / \mathrm{H}$ and oral valproic acid. Apmis. 2006; 114 (10): 731-43.

9. Freeman Al, Zakay-Rones Z, Gomori JM, Linetsky E, Rasooly L, Greenbaum E, et al. Phase I/Il trial of intravenous NDV-HUJ oncolytic virus in recurrent glioblastoma multiforme. Mol Ther 2006; 13 (1): 221-28.

10. Csatary LK, Gosztonyi G, Szeberenyi J, Fabian Z, Liszka V, Bodey $\mathrm{B}$, et al. MTH-68/H oncolytic viral treatment in human highgrade gliomas. J Neurooncol. 2004; 67 (1-2): 83-93.

11. Csatary LK, Bakacs T. Use of Newcastle disease virus vaccine $(\mathrm{MTH}-68 / \mathrm{H})$ in a patient with high-grade glioblastoma. JAMA. 1999; 281 (17): 588-89.

12. Tsamis Kl, Alexiou GA, Vartholomatos E, Kyritsis AP. Combination treatment for glioblastoma cells with tumor necrosis factor-related apoptosis-inducing ligand and oncolytic adenovirus delta-24. Cancer Invest. 2013; 31 (9): 630-38. DOI: 10.3109/07357907.2013.849724. PubMed PMID: 24164301.

13. Li X, Mao Q, Wang D, Xia H. A novel Ad5/11 chimeric oncolytic adenovirus for improved glioma therapy. Int J Oncol. 2012; 41 (6): 2159-65. DOI: 10.3892/jo.2012.1674. PubMed PMID: 23117867.

14. Alonso MM, Jiang H, Gomez-Manzano C, Fueyo J. Targeting brain tumor stem cells with oncolytic adenoviruses. Methods Mol Biol. 2012; 797: 111-25

15. Ahmed AU, Ulasov IV, Mercer RW, Lesniak MS. Maintaining and loading neural stem cells for delivery of oncolytic adenovirus to brain tumors. Methods Mol Biol. 2012; 797: 97-109.

16. Gomez-Manzano C, Fueyo J. Oncolytic adenoviruses for the treatment of brain tumors. Curr Opin Mol Ther. 2010; 12 (5): 53037.

17. Lacroix J, Schlund F, Leuchs B, Adolph K, Sturm D, Bender S, et al. Oncolytic effects of parvovirus $\mathrm{H}-1$ in medulloblastoma are associated with repression of master regulators of early neurogenesis. Int J Cancer. 2014; 134 (3): 703-16. DOI: 10.1002 ijc.28386. PubMed PMID: 23852775.

18. Paglino JC, Ozduman K, van den Pol AN. Lulll parvovirus selectively and efficiently targets, replicates in, and kills human glioma cells. J Virol. 2012; 86 (13): 7280-91

19. Geletneky K, Huesing J, Rommelaere J, Schlehofer JR, Leuchs B, Dahm M, et al. Phase 1/lla study of intratumoral/intracerebral or intravenous/intracerebral administration of Parvovirus $\mathrm{H}-1$ (ParvOryx) in patients with progressive primary or recurrent glioblastoma multiforme: ParvOryx01 protocol. BMC cancer. 2012; 12: 99

20. Kicielinski KP, Chiocca EA, Yu JS, Gill GM, Coffey M, Markert JM. Phase 1 clinical trial of intratumoral reovirus infusion for the treatment of recurrent malignant gliomas in adults. Mol Ther. 2014; 22 (5): 1056-62. DOI: 10.1038/mt.2014.21. PubMed PMID: 24553100; PubMed Central PMCID: PMCPMC4015229.

21. van den Wollenberg DJ, Dautzenberg IJ, van den Hengel SK, Cramer SJ, de Groot RJ, Hoeben RC. Isolation of reovirus T3D mutants capable of infecting human tumor cells independent of junction adhesion molecule-A. PLoS One. 2012; 7 (10): e48064. DOI: 10.1371/journal.pone.0048064. PubMed PMID: 23110175; PubMed Central PMCID: PMCPMC3480499.

22. Forsyth P, Roldan G, George D, Wallace C, Palmer CA, Morris D, et al. A phase I trial of intratumoral administration of reovirus in patients with histologically confirmed recurrent malignant gliomas. Mol Ther. 2008; 16 (3): 627-32.

23. Wilcox ME, Yang W, Senger D, Rewcastle NB, Morris DG, Brasher PM, et al. Reovirus as an oncolytic agent against experimental human malignant gliomas. J Natl Cancer Inst. 2001; 93 (12): 903-12. PubMed PMID: 11416111.

24. Goetz C, Dobrikova E, Shveygert M, Dobrikov M, Gromeier M. Oncolytic poliovirus against malignant glioma. Future Virol. 2011; 6 (9): 1045-58.

25. Goetz C, Gromeier M. Preparing an oncolytic poliovirus recombinant for clinical application against glioblastoma multiforme. Cytokine Growth Factor Rev. 2010; 21 (2-3): 197-203. DOI: 10.1016/j.cytogfr.2010.02.005. PubMed PMID: 20299272; PubMed Central PMCID: PMCPMC2881183.

26. Dobrikova EY, Broadt T, Poiley-Nelson J, Yang X, Soman G, Giardina S, et al. Recombinant oncolytic poliovirus eliminates glioma in vivo without genetic adaptation to a pathogenic phenotype. Mol Ther. 2008; 16 (11): 1865-72.

27. Gromeier M, Lachmann S, Rosenfeld MR, Gutin PH, Wimmer E. Intergeneric poliovirus recombinants for the treatment of malignant glioma. Proc Natl Acad Sci USA. 2000; 97 (12): 6803-08.

28. Lawler SE, Speranza MC, Cho CF, Chiocca EA. Oncolytic Viruses in Cancer Treatment: A Review. JAMA oncology. 2017; 3 (6): 841-49. DOI: 10.1001/jamaoncol.2016.2064. PubMed PMID: 27441411.

29. Pol J, Buque A, Aranda F, Bloy N, Cremer I, Eggermont A, et al. Trial Watch-Oncolytic viruses and cancer therapy. Oncoimmunology. 2016; 5 (2): e1117740. DOI: 10.1080/2162402x.2015.1117740. PubMed PMID: 27057469; PubMed Central PMCID: PMCPMC4801444.

30. Taguchi S, Fukuhara H, Homma Y, Todo T. Current status of clinical trials assessing oncolytic virus therapy for urological cancers. Int J Urol. 2017; 24 (5): 342-51. DOI: 10.1111/iju.13325. PubMed PMID: 28326624

31. Warner SG, O'Leary MP, Fong Y. Therapeutic oncolytic viruses: clinical advances and future directions. Curr Opin Oncol. 2017; 
29 (5): 359-65. DOI: 10.1097/cco.0000000000000388. PubMed PMID: 28678032.

32. Bach P, Abel T, Hoffmann C, Gal Z, Braun G, Voelker I, et al. Specific elimination of CD133+ tumor cells with targeted oncolytic measles virus. Cancer Res. 2013; 73 (2): 865-74. DOI: 10.1158/0008-5472.can-12-2221. PubMed PMID: 23293278.

33. Berghauser Pont LM, Balvers RK, Kloezeman JJ, Nowicki MO, van den Bossche W, Kremer A, et al. In vitro screening of clinical drugs identifies sensitizers of oncolytic viral therapy in glioblastoma stem-like cells. Gene Ther. 2015. DOI: 10.1038/ gt.2015.72. PubMed PMID: 26196249.

34. Dey M, Ulasov IV, Lesniak MS. Virotherapy against malignant glioma stem cells. Cancer Lett. 2010; 289 (1): 1-10.

35. Liu J, Ma L, Xu J, Liu C, Zhang J, Liu J, et al. Spheroid bodyforming cells in the human gastric cancer cell line MKN-45 possess cancer stem cell properties. Int J Oncol. 2013; 42 (2): 453-59. DOI: 10.3892/ijo.2012.1720. PubMed PMID: 23229446; PubMed Central PMCID: PMCPMC3583623.

36. Sgubin D, Wakimoto H, Kanai R, Rabkin SD, Martuza RL. Oncolytic herpes simplex virus counteracts the hypoxia-induced modulation of glioblastoma stem-like cells. Stem cells translational medicine. 2012; 1 (4): 322-32. DOI: 10.5966/sctm.2011-0035. PubMed PMID: 23197811; PubMed Central PMCID: PMCPMC3659700.

37. van den Hengel SK, Balvers RK, Dautzenberg IJ, van den
Wollenberg DJ, Kloezeman JJ, Lamfers ML, et al. Heterogeneous reovirus susceptibility in human glioblastoma stem-like cell cultures. Cancer Gene Ther. 2013; 20 (9): 507-13. DOI: 10.1038/ cgt.2013.47. PubMed PMID: 23907517.

38. Чумаков П. М., Морозова В. В., Бабкин И. В., Байков И. К., Нетесов С. В., Тикунова Н. В. Онколитические энтеровирусы. Молекулярная биология. 2012; 46 (6): 712-25.

39. Ворошилова М. К., Магазаник С. С., Чумаков П. М. Полезные вирусы человека. Актуальные вопросы эпидемиологии, микробиологии и инфекционных заболеваний. Ташкент: Медицина; 1980. р. 227-29.

40. Wang $X$, Yang $K$, Xie $Q$, Wu Q, Mack SC, Shi $Y$, et al. Purine synthesis promotes maintenance of brain tumor initiating cells in glioma. Nature neuroscience. 2017; 20 (5): 661-73. DOI: 10.1038/nn.4537. PubMed PMID: 28346452; PubMed Central PMCID: PMCPMC6015494.

41. Lathia JD, Mack SC, Mulkearns-Hubert EE, Valentim CL, Rich JN Cancer stem cells in glioblastoma. Genes Dev. 2015; 29 (12): 1203-17. DOI: 10.1101/gad.261982.115. PubMed PMID: 26109046; PubMed Central PMCID: PMCPMC4495393.

42. Desjardins A, Gromeier M, Herndon JE, 2nd, Beaubier N, Bolognesi DP, Friedman AH, et al. Recurrent Glioblastoma Treated with Recombinant Poliovirus. N Engl J Med. 2018; DOI: 10.1056/ NEJMoa1716435. PubMed PMID: 29943666

\section{References}

1. Gubanova NV, Gaytan AS, Razumov IA, Mordvinov VA, Krivoshapkin AL, Netesov SV, i dr. Onkoliticheskie virusy v terapii gliom. Molekuljarnaja biologija. 2012; 46 (6): 726-38.

2. Greenberg MS. Handbook of Neurosurgery. 7th ed. New York: Thieme Publishers; 2010.

3. Park DM, Rich JN. Biology of glioma cancer stem cells. Molecules and cells. 2009; 28 (1): 7-12. DOI: 10.1007/s10059-009-0111-2. PubMed PMID: 19655094.

4. Claes A, Idema AJ, Wesseling P. Diffuse glioma growth: a guerilla war. Acta Neuropathol. 2007; 114 (5): 443-58. DOI: 10.1007/ s00401-007-0293-7. PubMed PMID: 17805551; PubMed Central PMCID: PMCPMC2039798.

5. Buonaguro FM, Tornesello ML, Izzo F, Buonaguro L. Oncolytic virus therapies. Pharmaceutical patent analyst. 2012; 1 (5): $621-$ 27. DOI: 10.4155/ppa.12.65. PubMed PMID: 24236929.

6. Parker JN, Bauer DF, Cody JJ, Markert JM. Oncolytic viral therapy of malignant glioma. Neurotherapeutics. 2009; 6 (3): 558-69.

7. Zulkifli MM, Ibrahim R, Ali AM, Aini I, Jaafar H, Hilda SS, et al. Newcastle diseases virus strain V4UPM displayed oncolytic ability against experimental human malignant glioma. Neurological research. 2009; 31 (1): 3-10. DOI: 10.1179/174313208×325218. PubMed PMID: 18937888

8. Wagner S, Csatary CM, Gosztonyi G, Koch HC, Hartmann C, Peters $\mathrm{O}$, et al. Combined treatment of pediatric high-grade glioma with the oncolytic viral strain $\mathrm{MTH}-68 / \mathrm{H}$ and oral valproic acid. Apmis. 2006; 114 (10): 731-43.

9. Freeman Al, Zakay-Rones Z, Gomori JM, Linetsky E, Rasooly L, Greenbaum E, et al. Phase 1/II trial of intravenous NDV-HUJ oncolytic virus in recurrent glioblastoma multiforme. Mol Ther. 2006; 13 (1): 221-28.

10. Csatary LK, Gosztonyi G, Szeberenyi J, Fabian Z, Liszka V, Bodey B, et al. MTH-68/H oncolytic viral treatment in human highgrade gliomas. J Neurooncol. 2004; 67 (1-2): 83-93.

11. Csatary LK, Bakacs T. Use of Newcastle disease virus vaccine (MTH-68/H) in a patient with high-grade glioblastoma. JAMA. 1999; 281 (17): 588-89.

12. Tsamis KI, Alexiou GA, Vartholomatos E, Kyritsis AP. Combination treatment for glioblastoma cells with tumor necrosis factor-related apoptosis-inducing ligand and oncolytic adenovirus delta-24. Cancer Invest. 2013; 31 (9): 630-38. DOI: 10.3109/07357907.2013.849724. PubMed PMID: 24164301.

13. Li X, Mao Q, Wang D, Xia H. A novel Ad5/11 chimeric oncolytic adenovirus for improved glioma therapy. Int J Oncol. 2012; 41

(6): 2159-65. DOI: 10.3892/ijo.2012.1674. PubMed PMID: 23117867.

14. Alonso MM, Jiang H, Gomez-Manzano C, Fueyo J. Targeting brain tumor stem cells with oncolytic adenoviruses. Methods Mol Biol. 2012; 797: 111-25

15. Ahmed AU, Ulasov IV, Mercer RW, Lesniak MS. Maintaining and loading neural stem cells for delivery of oncolytic adenovirus to brain tumors. Methods Mol Biol. 2012; 797: 97-109.

16. Gomez-Manzano C, Fueyo J. Oncolytic adenoviruses for the treatment of brain tumors. Curr Opin Mol Ther. 2010; 12 (5): 53037.

17. Lacroix J, Schlund F, Leuchs B, Adolph K, Sturm D, Bender S, et al. Oncolytic effects of parvovirus $\mathrm{H}-1$ in medulloblastoma are associated with repression of master regulators of early neurogenesis. Int J Cancer. 2014; 134 (3): 703-16. DOI: 10.1002/ ijc.28386. PubMed PMID: 23852775.

18. Paglino JC, Ozduman K, van den Pol AN. Lulll parvovirus selectively and efficiently targets, replicates in, and kills human glioma cells. J Virol. 2012; 86 (13): 7280-91.

19. Geletneky K, Huesing J, Rommelaere J, Schlehofer JR, Leuchs B, Dahm $M$, et al. Phase I/lla study of intratumoral/intracerebral or intravenous/intracerebral administration of Parvovirus $\mathrm{H}-1$ (ParvOryx) in patients with progressive primary or recurrent glioblastoma multiforme: ParvOryx01 protocol. BMC cancer. 2012; 12: 99.

20. Kicielinski KP, Chiocca EA, Yu JS, Gill GM, Coffey M, Markert JM. Phase 1 clinical trial of intratumoral reovirus infusion for the treatment of recurrent malignant gliomas in adults. Mol Ther. 2014; 22 (5): 1056-62. DOl: 10.1038/mt.2014.21. PubMed PMID: 24553100; PubMed Central PMCID: PMCPMC4015229.

21. van den Wollenberg DJ, Dautzenberg IJ, van den Hengel SK, Cramer SJ, de Groot RJ, Hoeben RC. Isolation of reovirus T3D mutants capable of infecting human tumor cells independent of junction adhesion molecule-A. PLoS One. 2012; 7 (10): e48064. DOI: 10.1371/journal.pone.0048064. PubMed PMID: 23110175; PubMed Central PMCID: PMCPMC3480499.

22. Forsyth P, Roldan G, George D, Wallace C, Palmer CA, Morris D, et al. A phase I trial of intratumoral administration of reovirus in patients with histologically confirmed recurrent malignant gliomas. Mol Ther. 2008; 16 (3): 627-32.

23. Wilcox ME, Yang W, Senger D, Rewcastle NB, Morris DG, Brasher PM, et al. Reovirus as an oncolytic agent against experimental human malignant gliomas. J Natl Cancer Inst. 2001; 
93 (12): 903-12. PubMed PMID: 11416111.

24. Goetz C, Dobrikova E, Shveygert M, Dobrikov M, Gromeier M. Oncolytic poliovirus against malignant glioma. Future Virol. 2011; 6 (9): 1045-58.

25. Goetz C, Gromeier M. Preparing an oncolytic poliovirus recombinant for clinical application against glioblastoma multiforme. Cytokine Growth Factor Rev. 2010; 21 (2-3): 197-203. DOI: 10.1016/j.cytogfr.2010.02.005. PubMed PMID: 20299272; PubMed Central PMCID: PMCPMC2881183.

26. Dobrikova EY, Broadt T, Poiley-Nelson J, Yang X, Soman G, Giardina $S$, et al. Recombinant oncolytic poliovirus eliminates glioma in vivo without genetic adaptation to a pathogenic phenotype. Mol Ther. 2008; 16 (11): 1865-72.

27. Gromeier M, Lachmann S, Rosenfeld MR, Gutin PH, Wimmer E. Intergeneric poliovirus recombinants for the treatment of malignant glioma. Proc Natl Acad Sci USA. 2000; 97 (12): 6803-08.

28. Lawler SE, Speranza MC, Cho CF, Chiocca EA. Oncolytic Viruses in Cancer Treatment: A Review. JAMA oncology. 2017; 3 (6): 841-49. DOI: 10.1001/jamaoncol.2016.2064. PubMed PMID: 27441411

29. Pol J, Buque A, Aranda F, Bloy N, Cremer I, Eggermont A, et al. Trial Watch-Oncolytic viruses and cancer therapy. Oncoimmunology. 2016; 5 (2): e1117740. DOI: 10.1080/2162402x.2015.1117740. PubMed PMID: 27057469; PubMed Central PMCID: PMCPMC4801444.

30. Taguchi S, Fukuhara H, Homma Y, Todo T. Current status of clinical trials assessing oncolytic virus therapy for urological cancers. Int J Urol. 2017; 24 (5): 342-51. DOI: 10.1111/iju.13325. PubMed PMID: 28326624.

31. Warner SG, O'Leary MP, Fong Y. Therapeutic oncolytic viruses: clinical advances and future directions. Curr Opin Oncol. 2017; 29 (5): 359-65. DOI: 10.1097/cco.0000000000000388. PubMed PMID: 28678032.

32. Bach P, Abel T, Hoffmann C, Gal Z, Braun G, Voelker I, et al. Specific elimination of CD133+ tumor cells with targeted oncolytic measles virus. Cancer Res. 2013; 73 (2): 865-74. DOI: 10.1158/0008-5472.can-12-2221. PubMed PMID: 23293278.

33. Berghauser Pont LM, Balvers RK, Kloezeman JJ, Nowicki MO, van den Bossche W, Kremer A, et al. In vitro screening of clinical drugs identifies sensitizers of oncolytic viral therapy in glioblastoma stem-like cells. Gene Ther. 2015. DOI: 10.1038/ gt.2015.72. PubMed PMID: 26196249.

34. Dey M, Ulasov IV, Lesniak MS. Virotherapy against malignant glioma stem cells. Cancer Lett. 2010; 289 (1): 1-10.

35. Liu J, Ma L, Xu J, Liu C, Zhang J, Liu J, et al. Spheroid bodyforming cells in the human gastric cancer cell line MKN-45 possess cancer stem cell properties. Int J Oncol. 2013; 42 (2): 453-59. DOI: 10.3892/ijo.2012.1720. PubMed PMID: 23229446; PubMed Central PMCID: PMCPMC3583623.

36. Sgubin D, Wakimoto H, Kanai R, Rabkin SD, Martuza RL. Oncolytic herpes simplex virus counteracts the hypoxia-induced modulation of glioblastoma stem-like cells. Stem cells translational medicine. 2012; 1 (4): 322-32. DOI: 10.5966/sctm.2011-0035. PubMed PMID: 23197811; PubMed Central PMCID: PMCPMC3659700.

37. van den Hengel SK, Balvers RK, Dautzenberg IJ, van den Wollenberg DJ, Kloezeman JJ, Lamfers ML, et al. Heterogeneous reovirus susceptibility in human glioblastoma stem-like cell cultures. Cancer Gene Ther. 2013; 20 (9): 507-13. DOI: 10.1038/ cgt.2013.47. PubMed PMID: 23907517.

38. Chumakov PM, Morozova W, Babkin IV, Baykov IK, Netesov SV, Tikunova NV. Onkoliticheskie enterovirusy. Molekuljarnaja biologija. 2012; 46 (6): 712-25.

39. Voroshilova MK, Magazanik SS, Chumakov PM. Poleznye virusy cheloveka. Aktual'nye voprosy epidemiologii, mikrobiologii infekzionnyh zabolevaniy. Tashkent: Medicina; 1980. p. 227-29.

40. Wang X, Yang K, Xie Q, Wu Q, Mack SC, Shi Y, et al. Purine synthesis promotes maintenance of brain tumor initiating cells in glioma. Nature neuroscience. 2017; 20 (5): 661-73. DOI: 10.1038/nn.4537. PubMed PMID: 28346452; PubMed Central PMCID: PMCPMC6015494.

41. Lathia JD, Mack SC, Mulkearns-Hubert EE, Valentim CL, Rich JN. Cancer stem cells in glioblastoma. Genes Dev. 2015; 29 (12): 1203-17. DOI: 10.1101/gad.261982.115. PubMed PMID: 26109046; PubMed Central PMCID: PMCPMC4495393.

42. Desjardins A, Gromeier M, Herndon JE, 2nd, Beaubier N, Bolognesi DP, Friedman AH, et al. Recurrent Glioblastoma Treated with Recombinant Poliovirus. N Engl J Med. 2018; DOI: 10.1056/ NEJMoa1716435. PubMed PMID: 29943666. 